\title{
CERTAIN CLASSES OF ANALYTIC FUNCTIONS WITH NEGATIVE COEFFICIENTS ASSOCIATED WITH A CONVOLUTION STRUCTURE
}

\section{G. Murugusundaramoorthy and S. B. Joshi}

Abstract. Making use of a convolution structure, we introduce a new class of analytic functions $\mathbb{P T}_{g}(\lambda, \alpha, \beta, \gamma)$ defined in the open unit disc and investigate its various characteristics. Further we obtained distortion bounds, extreme points and radii of close-to-convexity, starlikeness and convexity for functions belonging to the class $\mathbb{P T}_{g}(\lambda, \alpha, \beta, \gamma)$.

Mathematics subject classification (2000): 30C45.

Keywords and phrases: Analytic, univalent, starlikeness, convexity, Hadamard product (convolution).

\section{REFERENCES}

[1] O. Altintas, A subclass of analytic functions with negative coefficients, Bull. Sci-Engg. Hacettepe Univ., 19 (1990), 15-24.

[2] G. J. BAO AND Y. Ling, On Some classes of analytic functions with negative coefficients, J. Harbin Inst. Tech., 23 (1991), 100-103.

[3] B. C. CARlson AND D. B. ShAFFER, Starlike and prestarlike hypergeometric functions, SIAM J. Math. Anal., 15 (1984), 737-745.

[4] N. E. CHO AND T. H. KIM, Multiplier transformations and strongly close-to-convex functions, Bull. Korean Math. Soc., 40, 3 (2003), 399-410.

[5] N. E. Cho AND H. M. SRivastava, Argument estimates of certain analytic functions defined by a class of multiplier transformations, Math. Comput. Modelling, 37, 1-2 (2003), 39-49.

[6] J. DZIOK AND H. M. SRIVASTAVA, Classes of analytic functions associated with the generalized hypergeometric function, Appl. Math. Comput., 103, 1 (1999), 1-13.

[7] V. P. GUPTA AND P. K. JAIN, Certain classes of univalent functions with negative coefficients-II, Bull. Austral. Math. Soc., 15 (1976), 467-473.

[8] S. OWA AND S. K. LEE, Certain generalized class of analytic functions with negative coefficients, Bull. Cal. Math. Soc., 82 (1990), 284-289.

[9] J. Patel And A. K. Mohanty, On certain generalized class of analytic functions, Soochow J. Math., 23, 4 (1997), 365-379.

[10] G. Ş. SăLĂGEAN, Subclasses of univalent functions, Lect. Notes in Math. (Springer-Verlag), 1013 (1983), 362-372.

[11] S. M. SARANGI AND B. A. URALEGADDI, The radius of convexity and starlikeness for certain classes of analytic functions with negative coefficients, Atti. Acad. Naz. Lincci Rend. Sc. Fis. Mat. Natur., 45 (1978), 38-42.

[12] H. Silverman, Univalent functions with negative coefficients, Proc. Amer. Math. Soc., 51 (1975), $109-116$.

[13] S. Ruscheweyh, New criteria for univalent functions, Proc. Amer. Math. Soc., 49 (1975), 109-115.

[14] T. Yaguchi, T. Sekine, H. Saitoh, S. Owa, M. Nunokawa And S. Fukui, A generalization class of certain subclasses of analytic functions with negative coefficients, Proc. Inst. Natur. Sci. Nihon Univ., 25 (1990), 67-80. 